\title{
Los salarios en la industria azucarera cubana, central Santa María S. A. 1940
}

\author{
Yanetsy Marín Bermúdez ${ }^{1}$ \\ Yumaisi González Ochoa
}

Recibido: 14 de febrero de 2015

Aprobado: 15 de mayo de 2015

Marín, Y. \& González, Y. (2015). Los salarios en la industria azuca-

Clasificación JEL

N 00, N46

\section{Resumen}

La industria azucarera en Cuba representó una de las principales fuentes de ingreso del país desde mediados de la Colonia española. El Archivo del Patrimonio Histórico Azucarero de Villa Clara conserva documentos de los centrales de la actual provincia de Villa Clara, que datan desde 1845-2001. Entre estos documentos se relacionan 335 tomos de las nóminas, los sueldos y jornales de los obreros de estos centrales, 19 tomos que corresponden al

1 Licenciada en Contabilidad y Finanzas. Máster en Contabilidad Gerencial. Docente de la Licenciatura en Contabilidad y Finanzas, Facultad de Ciencias Económicas, Universidad Central "Marta Abreu” de Las Villas, Santa Clara, Cuba. Correo electrónico: yanetsym@uclv.edu.cu.

2 Licenciada en Contabilidad y Finanzas. Máster en Contabilidad Gerencial. Docente de la Licenciatura en Contabilidad y Finanzas, Facultad de Ciencias Económicas, Universidad Central "Marta Abreu” de Las Villas, Santa Clara, Cuba. Correo electrónico: yumaisigo@uclv.edu.cu 
Central Santa María S.A., actual Ifraín Alfonso, ubicado en el municipio de Ranchuelo. En la presente investigación se realiza un análisis históricocontable de la nómina de sueldos y jornales del Central Santa María S. A. en 1940, en el contexto de las regulaciones laborales vigentes en este periodo.

\title{
Palabras clave
}

Salarios, nóminas, industria azucarera, Cuba, historia de la contabilidad, Central Santa María S. A.

\section{Marín, B. \& González, O. (2015) .Wages in the Cuban sugar indus- try, Central Santa María S. A. 1940. Activos, 24, 103-138.}

\begin{abstract}
Ever since the middle of the Spanish colonial period, the sugar industry in Cuba represented one of the main income sources for the country. The Sugar Historical Patrimony Archive in the province of Villa Clara files lots of documents referring to the province current sugar-mills dating from the year 1845 to 2001 . 335 volumes of payrolls, salaries and daily wages are kept in that institution and 19 volumes correspond to the Former Santa María S. A. sugar mill, Ifrain Alfonso today, located in Ranchuelo town. The present research work deals with a countable-historical analysis of payrolls and wages at the Santa María S. A. sugar mill in the year 1940, according to the current period's regulations.
\end{abstract}

\section{Keywords}

Salary, payroll, sugar's industry, Cuba, accounting history, Central Santa María S. A. 


\section{Marín, B.\& González, O. (2015) .Les salaires au sein de l'industrie sucrière cubaine, centrale Sainte Marie S.A. 1940. Activos, 24, 103-138.}

\section{Résumé}

L'industrie sucrière à Cuba a représenté l' une des principales sources de revenus du pays depuis le milieu de la colonisation espagnole. L'archive du Patrimoine Historique Sucrier de Villa Clara conserve des documents des centrales de l'actuelle province Villa Clara qui datent de 1845 jusqu'à 2001. Parmi ces documents, on trouve 335 tomes sur les fiches de paie, les salaires et les journées de travail des ouvriers de ces centrales, 19 tomes qui correspondent à la Centrale Sainte Marie S.A., actuelle Ifraín Alfonso, située dans le municipe de Ranchuelo. Dans cette recherche, on réalise une analyse historico-comptable des salaires et des journées de travail de la Centrale Sainte Marie S.A. en 1940, dans le contexte des régulations de travail en vigueur à époque.

\section{Mots clés}

Salaires, paies, industrie sucrière, Cuba, histoire de la comptabilité, Centrale Sainte Marie S.A.

\section{Introducción}

La historia de la contabilidad es una disciplina que forma parte de la historia económica y que permite interpretar las dinámicas vividas en los negocios, las industrias, las empresas, los organismos estatales y otros, a partir del estudio de los documentos contables generados por estos en el pasado. Estos documentos contables se conservan generalmente en los archivos y en las bibliotecas de cada región o país. 
A partir de 2012 (Barrero y González, 2012), como parte de las investigaciones en historia de la contabilidad que realiza un grupo de profesores de la Universidad Central "Marta Abreu" de Las Villas, se inició el estudio del Archivo del Patrimonio Histórico Azucarero, ubicado en el local de la Asociación de Técnicos Azucareros de Cuba (ATAC) de la ciudad de Santa Clara. Este archivo fue creado en 2009 con vista a rescatar y conservar el patrimonio histórico azucarero villaclareño de las empresas azucareras que se desactivaron y de aquellas que permanecieron moliendo.

El Archivo del Patrimonio Histórico Azucarero concentra documentos referidos a los centrales de la actual provincia de Villa Clara, que datan desde 1845 hasta 2001. Entre estos documentos se conservan 335 tomos de las nóminas, sueldos y jornales de los obreros de estos centrales. El estudio histórico de la documentación contable generada por esta industria cobra singular importancia hoy en la conservación y el estudio del patrimonio azucarero villaclareño y cubano; especial connotación adquiere el tema salarial en la industria azucarera, que representó siempre el punto principal de las luchas obreras.

Las investigaciones y los estudios existentes sobre la industria azucarera cubana y el tema salarial en su mayoría están enfocados en la historia económica y social, pero se carece de investigaciones que consideren el estudio de los libros de nóminas conservados, específicamente en la etapa de la República, y su vínculo con las legislaciones laborales vigentes en dicho periodo.

Se toma como caso particular de esta investigación el libro de nóminas de sueldos y jornales de 1940, del Central Santa María S. A. ${ }^{3}$, actual Ifraín

3 El presente trabajo forma parte de la tesis de maestría de la profesora Yanetsy Marín, tesis que fue defendida en septiembre de 2015. Para el desarrollo de esta investigación, se contó con colaboración de los trabajadores de la Asociación de Técnicos Azucareros de Cuba en Santa Clara, del Archivo Histórico Provincial y trabajadores del actual Central Ifraín Alfonso. Es un estudio que se pretende extender como tema doctoral hacia el análisis de las nóminas conservadas de varios centrales de la región central del país. 
Alfonso, ubicado en el municipio de Ranchuelo de la provincia de Villa Clara, por ser este un central que permanece activo, y cuya cercanía a la ciudad de Santa Clara permitió la visita a su Sala de Historia, así como la posibilidad de entrevistar a personas que laboran allí incluso desde antes del triunfo de la Revolución; además, se conserva en el Archivo del Patrimonio Histórico Azucarero la Legislación Laboral de 1942, que describe la evolución de las regulaciones laborales desde 1938 hasta 1942.

El objetivo de la presente investigación es analizar la nómina de sueldos y jornales del Central Santa María S. A. en 1940, en el contexto de las regulaciones laborales vigentes en dicho año, como contribución a la historia de la contabilidad de la industria azucarera. Se presentan los resultados en cuatro acápites; el primero aborda el salario y las regulaciones laborales en la industria azucarera; en el segundo se expone la reseña histórica del Central Santa María S. A. y de sus características técnicas y productivas; el tercero muestra la regulación laboral y salarial para 1940; y en el último se analiza la nómina de sueldos y jornales del Central Santa María S. A. en el año en mención.

\section{El salario y las regulaciones laborales en la industria azucarera}

El salario tiene connotaciones muy diferentes para trabajadores y empleadores. Para estos últimos, aparte de ser un elemento del costo es un medio que permite motivar a los trabajadores. En cambio, para los trabajadores el salario representa el nivel de vida que pueden tener, un incentivo para adquirir calificaciones y una fuente de satisfacción frente al trabajo realizado. El pago de salarios en la industria azucarera en Cuba tiene sus particularidades, asociadas al propio desarrollo del cultivo de este producto, a la mano de obra empleada para las plantaciones azucareras y a los centrales, así como a las regulaciones laborales que han estado vigentes en cada periodo.

La caña de azúcar fue introducida en Cuba por Diego Velázquez en la segunda década del siglo XVI, y en poco tiempo se convirtió en la principal producción y fuente de ingresos del país. A la caña se dedicaron las mejores 
tierras de la isla; para hacerlas producir, llegaron desde remotos lugares miles de hombres y mujeres, muchos traídos por la fuerza y obligados a trabajar en las más brutales condiciones. Elaborar el azúcar con la mejor calidad para el mercado mundial se convirtió en el oficio cubano por excelencia. De acuerdo con Moreno (1978), desde finales del siglo XVIII, en los ingenios cubanos trabajaban tanto asalariados como esclavos.

En 1819 se introdujo en la isla la primera máquina de vapor, lo que dio inicio a la mecanización de la industria en todo el país y permitió eliminar gradualmente dos elementos costosos: el ganado de tiro, empleado en mover los trapiches, y la mano de obra esclava (Rebello, 1860).

El desarrollo tecnológico de la industria azucarera incrementó la demanda de obreros especializados, los cuales fueron desplazando a los esclavos, que por su poca o ninguna preparación eran incapaces de realizar otras labores que no fueran el corte, el alza y el tiro de la caña. La abolición definitiva de la esclavitud se hizo necesaria en 1886 por Real Orden de la Corona española (Torres-Cueva y Loyola, 2002).

Una vez abolida la esclavitud, los gastos que suponían el mantenimiento de los esclavos en comida, ropa y por enfermedad se transferían al pago de salario a los obreros contratados, lo cual proliferó el uso de las llamadas fichas para el pago del salario. Estas fichas fueron creadas por los hacendados con el carácter de monedas privadas para pagar con ellas los salarios de sus obreros, poniendo como pretexto la escasez de moneda fraccionaria circulante que padecía el país.

Con el cese de la dominación española y la aparición del nuevo orden republicano -influenciado, a su vez, por las protestas obreras-, el 23 de junio de 1909 se propició que el Congreso republicano acordara la Ley Arteaga. Esta ley prohibía el pago de salarios en cualquier especie diferente de la moneda en curso legal. Esta ley quedó recogida como la única normativa laboral de las primeras décadas del siglo XX, cuando las relaciones laborales se ajustaban a las débiles provisiones de la legislación civil (Zanetti, 2009, p. 40). 
La formación de numerosas organizaciones sindicales durante los años 20 y la activa participación de los obreros que condujeron al derrocamiento de la dictadura del presidente Gerardo Machado marcaron un punto de viraje, denotando la capacidad de paralizar todo el país. La primera medida de alto alcance en materia laboral fue el Decreto n. ${ }^{\circ} 1693$, que tuvo lugar durante el Gobierno provisional del presidente Ramón Grau San Martín; este decreto estableció la jornada laboral de ocho horas en todo el país. En el caso de la industria azucarera, esta disposición implicaba la introducción de un tercer turno durante la zafra.

En enero de 1934, los avances en materia de regulación laboral continuaron con la disposición del Decreto n. $^{\circ} 117$, que instituyó un jornal mínimo de 50 cincuenta centavos para el corte, el alza y el tiro por cada cien arrobas de caña. Esta acción representaba un salto con respecto a los 25 centavos pagados en la zafra de 1933. Luego, en 1935 surgió el primer sistema general de seguro obrero gracias al Decreto n. ${ }^{\circ} 1568$ de Maternidad Obrera, que reguló el procedimiento de contratos colectivos de trabajo y elevó a 80 centavos el jornal mínimo para las labores agrícolas en la zafra de dicho año.

En 1937 se promulgó la Ley de Coordinación Azucarera, que dedicó su capítulo $\mathrm{V}$ a la regulación de los salarios para las tareas agrícolas de la zafra. También se estableció la escala salarial en correspondencia con el precio del azúcar. Posteriormente, el Decreto n. ${ }^{\circ} 798$ de 1938 se consideró como el verdadero código de trabajo en tal época, que luego se consolidó por la Constitución de 1940, que recogía la obra legislativa de los seis años anteriores y elevaba su rango. El Acuerdo n. ${ }^{\circ} 50$ del 9 de enero de 1940 vino a complementar lo anteriormente establecido en el capítulo $\mathrm{V}$ del Reglamento de la Ley de Coordinación Azucarera; en este acuerdo se establecieron las tarifas de sueldo mínimo mensual o salario mínimo diario para empleados y obreros especializados de la industria azucarera.

La Segunda Guerra Mundial impulsó la recuperación de la cotización del azúcar, lo cual contribuyó a la demanda laboral y al incremento del $50 \%$ del salario, y se materializó en la zafra de 1942. En este periodo, la presión de los trabajadores impuso otros derechos, como la aplicación 
del descanso retribuido proporcional, que representó un $9.09 \%$ adicional a los salarios y que se amplió a los trabajos no regulares u ocasionales. Otra de las conquistas de 1942 fue el pago de los salarios al mismo nivel durante los doce meses del año, erradicando así el sistema de salarios en el tiempo muerto.

En el campo de la seguridad social, se instauró el retiro azucarero mediante la creación de la Caja del Retiro Social de Obreros y Empleados en la Industria Azucarera, la cual se nutría con aportes de colonos, hacendados y trabajadores. Se descontaban siete centavos por cada 100 arrobas de caña: cuatro centavos pagados por los colonos y tres por los obreros agrícolas.

Dos conquistas adicionales de los obreros azucareros en dicho periodo fueron el diferencial azucarero y la cláusula de garantía. De acuerdo con la Ley de Coordinación Azucarera, el salario de los obreros dependía del precio del azúcar, pero la venta de las zafras cubanas se hacía mayoritariamente a los Estados Unidos y sobre la base de un precio fijado de antemano. Los precios en el mercado internacional variaban y generalmente eran superiores al concertado con Estados Unidos, de ahí que los trabajadores cobraran menos de lo que podrían. A esta diferencia entre el precio de venta de la zafra a Estados Unidos y los azúcares exportados a otros países se le conoce como el diferencial azucarero (García, 1983).

Zanetti (2009) describe los términos de la cláusula de garantía: "La representación obrera participante en las negociaciones de las ventas globales de la zafra de 1946-1947 consiguió que los contratos incluyesen una cláusula de garantía, según la cual el precio del azúcar oscilaría de acuerdo con el índice de precios de productos básicos exportados por los Estados Unidos a Cuba". La implicación de esta cláusula determinó el pago de un diferencial de 29 millones de pesos sobre los salarios de la zafra de 1946 y mucho mayor en la zafra siguiente, que resultó la mejor pagada en la historia de la industria azucarera cubana. Estas y otras mejoras salariales en el periodo de 1940 a 1947 deben su triunfo a la destacada labor del general de las cañas, Jesús Menéndez Larrondo (García, 1983; Portilla, 1987). 
A finales de 1947, a raíz del descenso de las cotizaciones del azúcar en el mercado mundial, el gobierno decidió congelar los salarios al nivel equivalente de 4.96 centavos por libra, situación que, aunque tuvo varios intentos de cambio, se mantuvo hasta 1952. Los beneficios salariales obtenidos por los obreros hasta 1947 y la muerte de Jesús Menéndez Larrondo, líder sindical cubano, fueron hechos que influyeron de forma negativa (Zanetti, 2009, pp. 123-124).

La crisis, que ya era previsible, estalló con toda su fuerza en 1952 al concluir una inmensa zafra. El nuevo Gobierno de Batista retornó a la antigua práctica de las restricciones productivas y al papel regulador del Estado para lograr sostener los precios en declive. En 1953, la zafra se fijó en 5 millones de toneladas, el gobierno decidió descongelar los salarios y fijarlos al precio de 4.70 centavos por libra. Las zafras de 1954 y 1955 tuvieron nuevas restricciones que conllevaron a que en esta última se produjera una rebaja de los salarios hasta un nivel equivalente al precio de 4.40 centavos por libra.

En 1956 y 1957, con la extensión de la guerra desde la Sierra Maestra, el Gobierno de Batista aprovechó el alza de los precios del azúcar para colocar nuevamente los salarios a nivel de 4.96 centavos por libra, situación que no se mantuvo, pues en 1958 se redujeron los salarios hasta 4.70 centavos por libra; y para compensar esta rebaja, el gobierno pagó un diferencial que nadie había solicitado (Zanetti, 2009).

Una práctica común para estimular el pago de las labores azucareras entonces fue el conocido aguinaldo pagado en fin de año según decisión de los dueños de los centrales; este aguinaldo podía o no estar registrado en nómina y no representaba un monto fijo.

Antes de 1959, la jubilación en el sector azucarero era de 30 pesos mensuales, y cuando la pensión se transfería a otro miembro de la familia, apenas sus beneficiarios alcanzaban los 10 pesos mensuales, mientras que el presidente y los delegados de la Caja de Retiro aumentaban apreciablemente sus asignaciones y sueldos. Durante la presidencia del Dr. Bernardo 
Caramés (último ministro de Justicia de Batista) en la Caja de Retiro, la ley se modificó y pasó a privar del derecho de pensión a las viudas y a los hijos de los azucareros, así como también prohibió a los jubilados y pensionados desempeñar labores retribuidas en otro sector laboral, cualquiera que fuera el monto de su jubilación o pensión (Pacheco, 2008).

En su alegato de autodefensa, Fidel Castro Ruz proclamaba el derecho a luchar por la justicia social debido a las condiciones socioeconómicas del pueblo cubano en la década del 50 , entre las que se destacan un bajo crecimiento per cápita de la economía cubana y el declive del azúcar y de los salarios en casi todos los sectores, así como la prolongación de la jornada laboral a más de ocho horas en algunas industrias (Aguirre, 1964, citado en Pacheco, 2008).

Los cambios producidos en la industria azucarera con el triunfo de la Revolución y hasta nuestros días son resultado del entorno cambiante de la economía cubana. Profundizar en el pago salarial de este periodo no es objetivo de esta investigación.

\section{Reseña histórica del Central Santa María S. A. y de sus características técnicas y productivas}

La industria azucarera cubana durante la época de la República puede ser estudiada principalmente a partir de dos obras: los Anuarios azucareros de Cuba y los Manuales de la industria azucarera, la maquinaria y equipo de los ingenios.

La edición de los Anuarios inició en 1937 y estuvo a cargo de Cuba Económica y Financiera en la Habana. En su primera edición se resumen los datos conocidos de la industria azucarera desde 1902, fecha que marcó el inicio de la República. También contienen información en relación con la producción, la nacionalidad, el servicio de electricidad, el servicio telefónico, las industrias derivadas, los puertos y los almacenes de depósito, las principales vías férreas públicas y privadas, los precios del azúcar en 
todos los mercados, los impuestos que gravaban la producción municipal, provincial y nacional, entre otros datos estadísticos.

Por otra parte, los Manuales de la industria azucarera, la maquinaria y equipo de los ingenios, que eran editados por A. B. Gilmore en La Habana, describen en más detalle las características tecnológicas, de producción y de administración para cada uno de los centrales; además, muestran otros informes generales de la producción en el país.

En la presente investigación se hace uso de ambas obras para exponer y caracterizar el Central Santa María S. A. en 1940.

El primer propietario del central objeto de estudio fue Don Esteban Torriente, quien también fue su fundador. El Sr. Torriente se casó con Luisa Madrazo, con quien tuvo dos hijas, una de las cuales se casó con Don Esteban Cacicedo, que por herencia y otros negocios de familia pasó a ser dueño del central con el tiempo. Al morir Esteban Cacicedo, el ingenio fue heredado por su hijo, Felipe Cacicedo, quien fue su propietario hasta el 13 de octubre de 1960, cuando se llevó a cabo la nacionalización de la industria azucarera tras el triunfo de la Revolución cubana.

La fundación de este ingenio data de 1846, fecha en que ya la zona era azucarera, pues en ella funcionaban los ingenios Don Pelayo, San José de Pedroso, Argudín, San Rafael, El Rubí y otros, tanto en el término de Ranchuelo como en el de Cruces, todos inmediatos. Estos ingenios fabricaban azúcar moscabada y cucurucho por medios muy rudimentarios (González, 2012).

El ingenio Santa María S. A. tenía similares características técnicas al resto de los ingenios de la localidad. Al producirse la abolición de la esclavitud, la mayoría de estos ingenios, que no se sostenían por la fuerza de trabajo esclavo (San José de Pedroso y San Rafael) fueron absorbidos por el antiguo Santa María S. A.

Al quedar unido este ingenio con una línea de ferrocarril a la vía férrea de Cienfuegos a Santa Clara, pasó a la categoría de central. Este cambio tuvo 
lugar poco antes del comienzo de la guerra de 1895. Las estancias compartidas entre el central y la finca Carolina constituyeron una costumbre desde los primeros propietarios, pues también poseían otro ingenio en la finca. La casa matriz de este central radicaba en Cienfuegos, donde sus dueños tenían otras propiedades.

Durante el periodo de la Colonia y hasta la abolición de la esclavitud, como en el resto de los centrales de la isla, la principal mano obrera estuvo conformada por esclavos. Luego se incrementó la mano de obra asalariada donde casi todos eran inmigrantes españoles sin familias. Con la nacionalización del trabajo en Cuba, muchos cubanos ocuparon los puestos de trabajo en el central, vivían en el pueblo o en fincas vecinas, situación que les impedía formar grandes núcleos familiares en el batey. No se registra que existieran inmigrantes haitianos ni jamaicanos, siempre fueron españoles, lo cual le hizo ganar el sobrenombre de "La España Chiquita".

Se desconoce si en este central hubo sublevación de esclavos o participación de estos en la guerra de los Diez Años, o en la de 1895-98. Este central nunca fue atacado por los mambises, tampoco fue incendiado ni dañado de otra forma. En la guerra de 1895 tenía dos fortines: uno al noroeste y otro al suroeste, donde existían guarniciones españolas.

El terreno propiedad del central abarcaba 160 caballerías. Más del $75 \%$ de las tierras estaban destinadas a potreros para la crianza de ganado, mientras que el resto fue dispuesto para siembra de cañas. El abastecimiento de caña era de un $5 \%$ de la administración, y un $95 \%$ procedía de colonos. Había colonos con áreas de menos de diez caballerías, que hacían el $98 \%$, y otros entre diez y veinte caballerías, que constituían el $2 \%$. Muchos de estos colonos trabajaban la tierra con sus familiares, otros tenían que pagar jornales o trabajos a destajos. En conjunto, en las áreas cañeras trabajaban durante la zafra de 1600 a 1700 obreros, distribuidos entre pequeños y grandes colonos, así como en la parte de las cañas propias del central.

La maquinaria primitiva comenzó con una máquina de balancín, en la que el guarapo se cocinaba en diez pailas que formaban un tren común, a 
fuego directo en unas hornillas hechas a ras de tierra. Esta maquinaria fue mejorando a fines del pasado siglo, y las mejoras se hicieron más amplias a partir de 1910, cuando las máquinas de balancín se sustituyeron por máquinas alemanas, se instalaron tachos, cristalizadores, condensadores, bombas de alimentación para las calderas, bombas de vacíos y otros elementos técnicos. La primera locomotora, la n. ${ }^{0} 1$, se adquirió en 1916, año en que se construyó una chimenea de ladrillo refractario que sustituyó las antiguas de hierro.

En 1921 se agrandó la casa de calderas y se instalaron un clarificador moderno y otros equipos de evaporación y cocido. En el 1930, las prensas se cambiaron por un filtro Cliver, y la molida se aumentó de 175000 a 200000 arrobas cada 24 horas.

Al principio de esta industria, la leña y el bagazo eran los combustibles empleados. El bagazo que salía casi entero conservaba una gran cantidad de azúcar y era un buen combustible, que había que secar al sol y guardarlo en una casa de bagazo, tarea que realizaban los esclavos y los criollos que eran menores, hijos de esclavos. Más tarde comenzó a emplearse la hulla o carbón de piedra y, por último, el petróleo. Todos estos combustibles fueron usados para fortalecer la acción calorífica del bagazo, que sigue siendo el combustible base.

Para la transportación de los chichos distantes había $10 \mathrm{~km}$ de vía ancha, 144 carros de acero y dos locomotoras de 18 x 24 American Baldwin. Para transportar la caña más cercana había camiones que transitaban por la carretera que une el central con la de Cienfuegos a Santa Clara, y carretas que se movilizaban por guardarrayas; este último era el tramo más difícil, sobre todo cuando las lluvias comenzaban. El sistema de pesas era por romanas y básculas, unas instaladas en los chuchos y otras en el batey, con una romana para repesar carros de ferrocarril.

Se añade a los datos presentados con anterioridad, y a partir de los Anuarios, la siguiente información de este central en 1940 y los resultados de la zafra de dicho año. 
Tabla 1. Datos de la zafra del año 1940 para el Central Santa María S. A.

\begin{tabular}{l|r}
\hline \multicolumn{1}{c}{ Datos de la zafra de $\mathbf{1 9 4 0}$} \\
\hline Producción s /.325LBs. & 91486 \\
\hline Rendimiento 96\% & 12.04 \\
\hline Arrobas de caña molidas para producir azúcar & 9919000 \\
\hline Caballerías cortadas para azúcar & 187.36 \\
\hline Arrobas de caña por caballería cortada para azúcar & 52940 \\
\hline Arrobas de caña molidas para la producción de mieles & 5855050 \\
\hline Galones de mieles ricas invertidas & 2254550 \\
\hline Galones de producción de mieles finales & 509759 \\
\hline Galones de miel final por cada 100 arrobas de caña & 5.14 \\
\hline Días de zafra & 76 \\
\hline Días efectivos de molienda & 69 \\
\hline $\begin{array}{l}\text { Número aproximado de obreros en el campo y en el batey } \\
\text { utilizados en la zafra }\end{array}$ & 2000 \\
\hline
\end{tabular}

Colonos $424 \quad 1$ Por administración y 423 con contratos.

Fuente: elaboración propia a partir de los Anuarios azucareros de Cuba (1941).

La localidad de Ranchuelo se reconocía en días de la República por poseer una fuerte burguesía y un pobre movimiento obrero, caso que se reflejaba en los pobladores del batey del Central Santa María S. A. y en sus dueños. No obstante, no faltaron figuras destacadas en esta localidad, tal es el caso de Ifraín Alfonso, mártir revolucionario, cuyo nombre lleva actualmente el central.

\section{Regulación laboral y salarial para el año 1940}

El Acuerdo n. ${ }^{\circ} 50$ del 9 de enero de 1940, publicado en la Gaceta Oficial de la República el día 12 del mismo mes, fecha en que entró en vigor, vino a complementar lo establecido en el capítulo V del Reglamento de la Ley de Coordinación Azucarera. Este Acuerdo fue establecido por la Comisión Nacional de Salarios Mínimos (Pérez, 1942). 
En el artículo 1 de este acuerdo se explica que los salarios mínimos expuestos en el artículo 2 (tabla 2) se establecían como medida económica permanente mientras el precio promedio del azúcar se encontrara entre \$1.50- \$1.60, y a partir de estos precios, los salarios mínimos tendrían carácter flexible. Los salarios aparecen agrupados por departamentos y muestran la totalidad de trabajos vinculados a la producción de azúcar, de tal manera que fuese aplicable a todos los centrales, independientemente de su desarrollo tecnológico.

Con carácter comparativo, en la tabla 2 se añade una columna a lo establecido por la legislación azucarera para ese año, en la que se muestra el salario mensual de varios trabajadores del Central Santa María S. A. en dos de los meses de zafra, salarios que fueron tomados de la nómina de sueldos y jornales de 1940. Solo se presentan las labores que aparecen registradas en la nómina del Central Santa María S. A.

Tabla 2. Tarifa de sueldo mínimo mensual o salario mínimo diario para empleados y obreros especializados de la industria azucarera

\begin{tabular}{|c|c|c|c|}
\hline Departamentos & \multicolumn{2}{|c|}{ Legislación } & \multirow{2}{*}{$\begin{array}{c}\text { Central Santa } \\
\text { María S. A., } \\
\text { meses Feb.- } \\
\text { marzo, } 1940 \\
\begin{array}{c}\text { Salario } \\
\text { mensual }\end{array} \\
\end{array}$} \\
\hline A. Departamento de Campo & $\begin{array}{l}\text { Salario } \\
\text { mensual }\end{array}$ & $\begin{array}{c}\text { Salario } \\
\text { diario }\end{array}$ & \\
\hline Inspector de campo & 70.50 & 2.35 & $\$ 40.00$ \\
\hline Pesador de caña batey (carreta) & 59.10 & 1.97 & 91.00 \\
\hline \multicolumn{4}{|l|}{ B. Departamento de Batey } \\
\hline \multicolumn{4}{|l|}{ C. Salario de maquinaria } \\
\hline Segundo de maquinaria & 150.00 & 5.00 & 150.00 \\
\hline Jefe de taller & 100.00 & 3.33 & 209.00 \\
\hline Mecánico tornero & 82.50 & 2.75 & 145.00 \\
\hline Auxiliar de molida & 72.00 & 2.40 & 36.00 \\
\hline Virador de carros (basculador) & 42.00 & 1.40 & 80.00 \\
\hline Alimentador estera de caña & 42.00 & 1.40 & $47.00-49.00$ \\
\hline Ayudante máquina (cuchillas) & 42.00 & 1.40 & 54.00 \\
\hline Ayudante Máq. (tándem uno o dos trapiches) & 49.50 & 1.65 & 60.00 \\
\hline Ayudante Máq. (tándem tres o más trapiches) & 52.50 & 1.75 & 67.00 \\
\hline
\end{tabular}




\begin{tabular}{|c|c|c|c|}
\hline \multirow[t]{2}{*}{ Departamentos } & \multicolumn{2}{|c|}{ Legislación } & \multirow{2}{*}{$\begin{array}{c}\text { Central Santa } \\
\text { María S. A., } \\
\text { meses Feb.- } \\
\text { marzo, } 1940 \\
\begin{array}{c}\text { Salario } \\
\text { mensual }\end{array}\end{array}$} \\
\hline & $\begin{array}{l}\text { Salario } \\
\text { mensual }\end{array}$ & $\begin{array}{c}\text { Salario } \\
\text { diario }\end{array}$ & \\
\hline Ayudante de bombas & 42.00 & 1.40 & 80.00 \\
\hline Engrasadores de molinos & 39.00 & 1.30 & 47.00 \\
\hline Capataz de basculador & 45.00 & 1.50 & 67.00 \\
\hline Operario herrero & 78.00 & 2.60 & 104.00 \\
\hline Auxiliar herrero (majador) & 42.00 & 1.40 & 44.00 \\
\hline Operario pailero & 82.50 & 2.75 & 80.00 \\
\hline Alimentador de bagazo & 39.00 & 1.30 & 44.00 \\
\hline Limpiador de hornos (candelero o fogonero) & 52.50 & 1.75 & 80.00 \\
\hline \multicolumn{4}{|l|}{ D. Departamento de Electricidad } \\
\hline \multicolumn{4}{|l|}{ (Ingenio total o parcialmente electrificado) } \\
\hline \multicolumn{4}{|l|}{ (Ingenio no electrificado) } \\
\hline Electricista & 78.00 & 2.60 & 63.00 \\
\hline Ayudante de electricidad & 46.50 & 1.55 & 53.00 \\
\hline \multicolumn{4}{|l|}{ E. Departamento de Locomotora } \\
\hline Corredor locomotora vía pública & 105.00 & 3.50 & 145.00 \\
\hline Fogonero locomotora vía pública & 60.00 & 2.00 & 93.00 \\
\hline Fogonero locomotora vía interior & 49.50 & 1.65 & 49.00 \\
\hline Fogonero locomotora patio & 48.00 & 1.00 & 49.00 \\
\hline Capataz de reparación de vías & 51.00 & 1.70 & 110.00 \\
\hline \multicolumn{4}{|l|}{ F. Departamento de Fabricación } \\
\hline Terceros de defecación & 69.00 & 2.30 & 69.00 \\
\hline Jefe de tachos & 144.90 & 4.83 & 159.00 \\
\hline Puntistas & 105.00 & 3.50 & 120.00 \\
\hline Auxiliar de puntistas & 67.50 & 2.25 & 95.00 \\
\hline Ayudante de tachos & 45.00 & 1.50 & 45.00 \\
\hline Tripleros & 60.00 & 2.00 & 80.00 \\
\hline Purgadores de primera y segunda & 46.50 & 1.55 & 52.00 \\
\hline Purgadores de tercera & 40.50 & 1.35 & 49.00 \\
\hline \multicolumn{4}{|l|}{ Peones especializados de defecación } \\
\hline Cocinadores de guarapo & 39.00 & 1.30 & 40.00 \\
\hline Corredores de guarapo & 39.00 & 1.30 & 40.00 \\
\hline Cocinadores de cachaza & 37.50 & 1.25 & 40.00 \\
\hline
\end{tabular}




\begin{tabular}{l|c|c|c}
\hline \multicolumn{1}{c|}{ Departamentos } & \multicolumn{2}{c}{ Legislación } & $\begin{array}{c}\text { Central Santa } \\
\text { María S. A., } \\
\text { meses Feb.- } \\
\text { marzo, 1940 }\end{array}$ \\
\hline Corredores de cachaza & \multicolumn{2}{c}{} & 40.00 \\
\hline Pesador de guarapo & 37.50 & 1.25 & 40.00 \\
\hline Alcalizador & 39.00 & 1.30 & 43.00 \\
\hline G. Piso de Azúcar & 39.00 & 1.30 & \\
\hline Capataz de Piso de Azúcar & & & 68.00 \\
\hline Cosedor de saco & 60.00 & 2.00 & 49.00 \\
\hline Marcador de sacos (manual) & 48.00 & 1.60 & 54.00 \\
\hline Carretilleros y embudos & 54.00 & 1.80 & 49.00 \\
\hline Estibadores (cargando a espaldas) & 42.00 & 1.40 & 90.00 \\
\hline Carretilleros de estiba & 90.00 & 3.00 & 57.00 \\
\hline H. Sección de Laboratorio & 48.00 & 1.60 & \\
\hline Segundo químico & & & 120.00 \\
\hline Químicos auxiliares & 105.00 & 3.50 & 100.00 \\
\hline Recogedor de muestras & 80.00 & 2.66 & 36.00 \\
\hline I. Sección de Carpintería & 36.00 & 1.20 & \\
\hline Jefe carpintero & & & 77.00 \\
\hline Carpintero de primera & 90.00 & 3.00 & 67.00 \\
\hline Carpintero de segunda & 60.00 & 2.00 & 53.00 \\
\hline J. Sección de Albañilería & 52.50 & 1.75 & Salario \\
\hline Operario albañil (cuchara) & Salario & Salario \\
mensual & diario & \\
\hline & 67.50 & 2.25 & 60.00 \\
\hline
\end{tabular}

Fuente: elaboración propia a partir del Artículo 2 del Acuerdo n. ${ }^{\circ} 50$ de la Comisión Nacional de Salarios Mínimos.

Las actividades de corte, alza y tiro de la caña, labores que no aparecen descritas en el Acuerdo n. ${ }^{\circ}$ 50, habían sido legisladas desde la zafra de 1938. Se establecía que cada cien arrobas de caña debían ser pagadas por los colonos, con arreglo al rendimiento promedio obtenido por los ingenios en el trienio anterior y en una proporción fija preestablecida por la ley. En el caso del Central Santa María S. A., no aparecen descritas en la nómina las labores corte, alza y tiro de la caña, pues la caña que entraba al central provenía en un $95 \%$ de los colonos, los que pagaban directamente a los obreros los trabajos de campo. 
Los pagos a los colonos no aparecen en los registros de nóminas, sino en los pagos a proveedores, libros de cuentas que no existen en el Archivo del Patrimonio Histórico Azucarero, solo los submayores de colonos de los años 1926 y 1933. Estos libros de cuentas tampoco existen en la Sala de Historia del central, pero por relatos de antiguos trabajadores, se sabe que los documentos del archivo del central fueron quemados en una ocasión en que se precisaba hacer uso del local que los conservaba.

Se evidencia que los salarios registrados en varias labores eran superiores a los salarios mínimos establecidos por la legislación. Una de las razones de esta diferencia puede estar dada por la aplicación del factor multiplicador, pero al consultar los precios del azúcar en almacén para 1940, estos nunca sobrepasaron el precio de \$1.60. Otra razón que debe ser considerada es el hecho de que, en este periodo, el central era administrado por Esteban Cacicedo, quien, como ya se expuso, gozaba de buen criterio entre los pobladores del batey por sus bondades y buenas relaciones con los trabajadores. No obstante, como se describe en el siguiente epígrafe, la nómina no contaba con una columna de firma del trabajador como constancia de que ese salario registrado fuera igual al monto cobrado por este.

Estos sueldos y salarios debían aplicarse íntegramente en los ingenios cuya producción de azúcar crudo fuera superior a 75000 sacos. Cuando la producción del ingenio fuera inferior a 75000 sacos, los salarios básicos y los sueldos serían rebajados en un 10 por ciento. En el central que se estudia, estos salarios podrían ser totalmente aplicables, pues la producción de sacos de azúcar sobrepasaba los 75000 .

En los restantes artículos el Acuerdo n. ${ }^{\circ} 50$ se establecía el incremento de los salarios en correspondencia al precio del azúcar. Para la más fácil aplicación del aumento correspondiente a los sueldos mínimos mensuales y salarios mínimos diarios fijados en el artículo 2, el artículo 12 proponía la aplicación del factor multiplicador expuesto en la tabla 3. Esta información debía ser colocada en un lugar visible del ingenio, de manera que los obreros pudieran saber el salario por cobrar al que tenían derecho. 
El sueldo mínimo mensual o salario mínimo diario establecido en el artículo 2, multiplicado por el factor correspondiente al precio de una libra de azúcar crudo en el almacén, de acuerdo con la tabla del artículo anterior, resultaba el sueldo mínimo mensual o salario mínimo diario por pagar, al que además se le aplicaba el aumento de 10 centavos por cada ocho horas de labor, siempre que dicho precio excediera el \$1.60.

Tabla 3. Precios de una libra de azúcar y factor multiplicador para el incremento salarial

\begin{tabular}{c|c|c|c}
\hline $\begin{array}{c}\text { Precio de una } \\
\text { libra de azúcar } \\
\text { en centavos y } \\
\text { fracción }\end{array}$ & $\begin{array}{c}\text { Factor } \\
\text { multiplicador } \\
\text { para obtener el } \\
\text { sueldo o salario } \\
\text { diario }\end{array}$ & $\begin{array}{c}\text { Precio de una } \\
\text { libra de azúcar } \\
\text { en centavos y } \\
\text { fracción }\end{array}$ & $\begin{array}{c}\text { Factor } \\
\text { multiplicador } \\
\text { para obtener el } \\
\text { sueldo o salario } \\
\text { diario }\end{array}$ \\
\hline 1.50 a 1.60 & 1.00 & 2.01 a 2.05 & 1.090 \\
\hline 1.60 a 1.75 & 1.00 & 2.06 a 2.10 & 1.105 \\
\hline 1.76 a 1.80 & 1.015 & 2.11 a 2.15 & 1.120 \\
\hline 1.81 a 1.85 & 1.030 & 2.16 a 2.20 & 1.135 \\
\hline 1.86 a 1.90 & 1.045 & 2.21 a 2.25 & 1.150 \\
\hline 1.91 a 1.95 & 1.060 & 2.26 a 2.30 & 1.165 \\
\hline 1.96 a 2.00 & 1.075 & 2.31 a 2.35 & 1.180 \\
\hline 2.36 a 2.40 & 1.195 & 2.91 a 2.95 & 1.360 \\
\hline 2.41 a 2.45 & 1.210 & 2.96 a 3.00 & 1.375 \\
\hline 2.46 a 2.50 & 1.225 & 3.01 a 3.05 & 1.390 \\
\hline 2.51 a 2.55 & 1.240 & 3.06 a 3.10 & 1.405 \\
\hline 2.56 a 2.60 & 1.255 & 3.11 a 3.15 & 1.420 \\
\hline 2.61 a 2.65 & 1.270 & 3.16 a 3.20 & 1.435 \\
\hline 2.66 a 2.70 & 1.285 & 3.21 a 3.25 & 1.450 \\
\hline 2.71 a 2.75 & 1.300 & 3.26 a 3.30 & 1.465 \\
\hline 2.76 a 2.80 & 1.315 & 3.31 a 3.35 & 1.480 \\
\hline 2.81 a 2.85 & 1330 & 3.36 a 3.40 & 1.495 \\
\hline 2.86 a 2.90 & 1.345 & 3.46 a 3.50 & 1.525 \\
\hline
\end{tabular}

Fuente: artículo 12 del Acuerdo n. ${ }^{\circ} 50$ de la Comisión Nacional de Salarios Mínimos.

Otras resoluciones emitidas en octubre y diciembre del propio año 1940 establecieron el pago de jornal en días festivos o de duelo nacional. Los patronos estaban obligados a abonarles los salarios correspondientes a 
estos días. Esta disposición era aplicable, por unidad de obra o de tiempo, a todo trabajador que hubiere prestado servicios a un solo patrono $\mathrm{o}$ a varios coligados durante las 44 horas laborales anteriores e inmediatas al día de fiesta o duelo de que se tratase.

\section{Análisis de la nómina de sueldos y jornales del Central Santa María S. A. (1940)}

El proceso de intervención y nacionalización de las compañías y/o empresas azucareras que operaban en Cuba entre 1959 y 1960 evidenció el tratamiento seguido en cuanto a sistemas contables durante la mayor parte de la República. Cada una de estas entidades tenía su propio sistema de contabilidad y costos adecuado a sus características y estructura, dentro de las normas generales dictadas por el Estado, y que obedecían, en gran medida, a los procedimientos del sistema tributario.

La principal industria del país en la etapa de la República carecía de normativas contables que estandarizaran la información emitida por cada uno de los centrales o compañías azucareras. En 1947, Manuel de J. Fernández Cepero, contador público y profesor de la Universidad de La Habana, editó el tomo I del libro Contabilidad de ingenios azucareros, uno de los más completos sobre la contabilidad y los gastos en el sector, y cuyos tomos II y III fueron editados en 1949. Entre sus objetivos principales se encontraba dar los primeros pasos para sentar las bases y estimular la estandarización de los estados financieros. La obra abarca el tema de la contabilidad azucarera a partir de estudiar en primer término el proceso productivo en detalle.

Fernández Cepero (1947) describe que, en lo referente a los análisis de los gastos y costos, diversos sistemas estaban presentes. Como mínimo, el análisis por elementos de gastos se estructuraba en tres conceptos básicos: labor (para el salario total), materiales y otros gastos. En lo que correspondía a los gastos de producción, el proceso productivo se seguía con más o menos apertura. Es de interés para esta investigación el primer elemento 
del gasto, el de labor, a partir del conocimiento de los montos salariales recogidos en la nómina.

La contabilidad se procesaba por vías manuales y mecanizadas, utilizando diferentes tecnologías, máquinas de saldo directo y otros procedimientos. Otra característica era que la contabilidad en algunos casos se localizaba en los propios centrales azucareros, y en otros casos se encontraba centralizada de manera total o parcial en oficinas de control que dichas compañías tenían en la ciudad de La Habana o en la ciudad de residencia del dueño del central. En el caso del Central Santa María S. A. en 1940, esta dirección radicaba en el propio central.

El Código de Comercio español implantado en Cuba desde la época colonial y vigente en Cuba hasta nuestros días, con modificaciones, establecía en su artículo 33 los libros de contabilidad de uso obligatorio, los que debían ser legalizados ante el juez municipal del distrito al que perteneciese el establecimiento mercantil, artículo 36. Los libros de nóminas no figuraban entre los libros de uso obligatorio, pero el artículo 34 establecía el uso de libros auxiliares que, aunque no estaban obligados a su legalización, si el dueño lo entendía, también podrían ser legalizarlos.

El libro de nómina de sueldos y jornales del Central Santa María S. A. inicia con su legalización, en este caso, frente al juez legal de la ciudad de Cienfuegos. Se hace constar que el libro ha sido presentado por el señor Esteban Cacicedo, quien para entonces fungía como presidente del central, y se indica el domicilio social de este, en la ciudad de Cienfuegos. Además, al final del libro se expone que será dedicado a libro de nómina de sueldos y jornales. Se describe la composición entre 301 folios dobles útiles, todas sus hojas selladas con el cuño del juzgado, y se indican las fechas en que el acto legal ocurrió y las firmas del juez y el secretario judicial. Pasa lo mismo con el libro destinado a mayor de colonos de 1929.

Esta práctica de legalización de los libros contables era usual en Europa desde la generalización del uso de la partida doble, tanto es así que, en su Tratado de las cuentas y las escrituras, Luca Pacioli (1494) dedica el capítulo 
siete a la buena costumbre de autenticar los libros de cuenta de los mercaderes, práctica que evita la duplicidad de libros y el plagio de sus datos.

El libro de nóminas de sueldos y jornales del Central Santa María S. A. de 1940, como se evidencia en la figura 1, contiene un total de 15 columnas (en cada hoja) en las que se recogen los siguientes datos:

1. Núm.: aparece el número del trabajador; cada mes comienza con el número uno, aunque no corresponda al mismo trabajador.

2. Nombre y apellidos: en algunos casos aparecen con dos apellidos, y en otras ocasiones con uno.

3. Nacionalidad: a partir de la nómina se corroboran las nacionalidades de los trabajadores (cubanos y españoles), lo cual no descarta que en otras labores que no aparezcan en la nómina fueran de otra nacionalidad. En algunos casos dicha columna aparece en blanco: sin nacionalidad.

4. Destino: describe la labor que realizaban (mayoral, peón, etc.).

5. Días del mes: aparece una cuadrícula para cada día del mes, todas de 31 días. Se marcaba con una X el día trabajado; si trabajaban medio día, también se lo señalaban. Pero el trabajo del día 31 no aparecía marcado, la misma situación de presentaba para los domingos de descanso.

6. Días trabajados: se refiere a la cantidad total de días trabajados en el mes.

7. Sueldo o jornal: corresponde al salario devengado en un día. En caso de los trabajadores que ganaban un salario fijo mensual o un salario pactado para el desempeño de una labor, el saldo es el mismo que la columna alcance, por ejemplo, capataz, sirvienta de la casa, carpintero y mayoral.

8. Alcance: saldo total ganado en correspondencia con los días trabajados en un mes.

9. La columna siguiente aparece en blanco para completar con la cuenta correspondiente, ya fuera efectivo a cuenta o anticipo. En ambos casos representaban deducciones al salario devengado final. 
10. Total devengado: contiene el importe total por pagar al trabajador, luego de haber rebajado las deducciones.

11. Horas: se dividen en tres columnas correspondientes a las horas trabajadas en el mes, que es igual a la cantidad de días trabajados en el mes por ocho horas de trabajo; la cantidad de horas trabajadas en todo el año hasta el mes anterior; y la columna total, que corresponde a la suma de las horas trabajadas en el mes más la cantidad de horas acumuladas, para dar el total de horas trabajadas en el año.

12. Altas:

13. Bajas: Ambas columnas (12 y 13) por lo general aparecen vacías.

14. Descanso: se menciona el nombre del día que no se trabajaba, que en casi todos coincide con el domingo, salvo algunas excepciones en que los días no trabajados eran los sábados; en estos casos, en la columna días del mes, los que no aparecen marcados como trabajados son los sábados, por ejemplo: un trabajador del establo, un policía y una sirvienta, labores en las que se necesita de la permanencia diaria de al menos una persona.

16. Observaciones: se refiere a pagos específicos justificando la función de los trabajadores, por ejemplo: médico, abogado, inspector. Solo a final del mes se presenta en esta columna el importe correspondiente al impuesto por maternidad obrera y campo no retribuido.

Figura1. Libro de nóminas sueldos y jornales del Central Santa María S. A., 1940

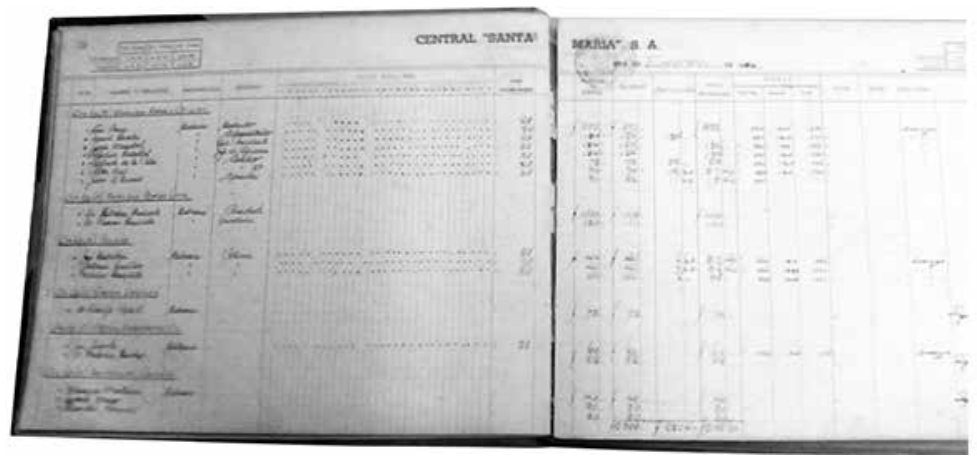

Fuente: tomado de la nómina de sueldos y jornales de la Central Santa María S. A., 1940. 
Al terminarse cada folio, se totalizaban las columnas correspondientes a saldos monetarios y se pasaban al siguiente folio, en el cual se reconocían en la primera fila, con el título De la vuelta. Estas columnas también se totalizaban al final de cada mes, práctica contable que se remonta a los inicios de la contabilidad como técnica.

Otra práctica contable que se evidencia en el libro de nóminas es el empleo del símbolo de gancho o punta de lanza $(\checkmark)$, utilizado para puntear las partidas o cantidades. El libro de nóminas incluye en la parte superior de cada página los horarios de los tres turnos de ocho horas de trabajo, así como también la hora de entrada y salida para aquellas labores continuas dentro del periodo de zafra.

La nómina se registraba por cuenta y subcuentas, con una nomenclatura en números para las cuentas y letras para las subcuentas, todas ellas asociadas a los distintos departamentos y procesos del central, tal como se explica a continuación.

La primera cuenta con las diferentes subcuentas que se registraba siempre en la nómina al inicio de cada mes es la 65 en el siguiente orden:

Tabla 4. Cuenta 65 y sus subcuentas con declaración de los salarios

\begin{tabular}{l|l|c|c}
\hline \multicolumn{1}{c|}{ Cuentas } & \multicolumn{1}{|c|}{ Cargo } & $\begin{array}{c}\text { Salario } \\
\text { mensual } \\
\text { hasta marzo }\end{array}$ & $\begin{array}{c}\text { Salario } \\
\text { mensual a } \\
\text { partir de abril }\end{array}$ \\
\hline \multirow{2}{*}{$\begin{array}{l}\text { 65(A) Sueldo de } \\
\text { administración general }\end{array}$} & Presidente & $\$ 1000.00$ & $\$ 1000.00$ \\
\cline { 2 - 4 } & Secretario & 150.00 & 150.00 \\
\hline \multirow{5}{*}{ 65(B) Sueldos de oficina } & Contador & 225.00 & 225.00 \\
\cline { 2 - 4 } & Administrador & 154.00 & 128.00 \\
\cline { 2 - 4 } & Vicepresidente & 154.00 & 128.00 \\
\cline { 2 - 4 } & Jefe de oficina & 154.00 & 128.00 \\
\cline { 2 - 4 } & Auxiliar 1 & 75.00 & 75.00 \\
\cline { 2 - 4 } & Auxiliar 2 & 70.00 & 56.00 \\
\cline { 2 - 4 } & Aprendiz & 25.00 & 20.00 \\
\hline
\end{tabular}




\begin{tabular}{l|l|c|c}
\hline \multicolumn{1}{c|}{ Cuentas } & \multicolumn{1}{c|}{ Cargo } & $\begin{array}{c}\text { Salario } \\
\text { mensual } \\
\text { hasta marzo }\end{array}$ & $\begin{array}{c}\text { Salario } \\
\text { mensual a } \\
\text { partir de abril }\end{array}$ \\
\hline 65(N) Policías & Policías 3 & 44.00 & 36.00 \\
\hline 65(C) Gastos legales & Abogado-Consultor & 75.00 & 75.00 \\
\hline $\begin{array}{l}\text { 65(I) Médicos, } \\
\text { enfermeros etc. }\end{array}$ & Enfermero & 60.00 & 50.00 \\
\cline { 2 - 4 } & Doctor & 25.00 & 25.00 \\
\hline $\begin{array}{l}\text { 65(O)Inspección de } \\
\text { colonias }\end{array}$ & Primero & 40.00 & 40.00 \\
\cline { 2 - 4 } & Otros 2 & 30.00 & 30.00 \\
\hline
\end{tabular}

Fuente: elaboración propia a partir de la nómina de sueldos y jornales del Central Santa María S. A., 1940

Estas subcuentas representan departamentos no considerados en la legislación laboral. Al revisar el libro de nóminas, se observa que en todo el periodo son las mismas personas y todas de nacionalidad cubana. Nótese que posterior al mes de marzo ocurre un descenso de algunos salarios, situación que se mantiene hasta diciembre y que se corresponde con el tiempo de zafra y el tiempo muerto. Lo mismo ocurre en 1941, con un incremento además del salario del presidente, don Esteban Cacicedo, a $\$ 1200.00$, y del secretario, Dr. Ramón Cacicedo, a $\$ 200.00$. Otros detalles de las subcuentas son explicados debajo en el orden que corresponde a la cuenta 65 .

Luego aparecen el resto de las cuentas indistintamente dispuestas en cada mes. La nomenclatura escrita en la nómina original para exponer los nombres de estas cuentas se conserva:

- Cuenta 61(A). Sueldos y jornales: los obreros que se registran son el mayoral, el auxiliar y los peones. Esta cuenta solo aparece en enero y es retomada en julio hasta diciembre. Al analizar la 64(N), se evidencia que el contenido es similar al de esta cuenta, y que solo aparece de febrero a junio, meses que no aparecen en la 61(A). Se nota, además, que el mayoral es la misma persona con el mismo salario en ambas cuentas, lo que lleva a inferir que se trata de una única cuenta. Puede entenderse que en los meses de zafra el gasto estuvo asociado a la cuenta $64(\mathrm{~N})$. 
- Cuenta 62: relacionada con las actividades del inciso E) Departamento de Locomotora, de la legislación.

- (A) Sueldos maquinistas: se corresponde con dos maquinistas con salario de $\$ 145.00$, que durante enero y de julio a diciembre aparecen registrados en esta cuenta. Pero en los meses de febrero a junio, en la subcuenta (B) asociada a los gastos del Departamento de Locomotora, son los mismos maquinistas con el mismo salario en todo el año. En el análisis de estas cuentas llama la atención que los hijos de estos dos maquinistas trabajaban como fogoneros, situación que era costumbre de la época, pues los padres enseñaban a sus hijos su oficio. En el análisis de esta nómina ocurre lo mismo con el hijo de Waldo García, superintendente y responsable de la producción, cuyo hijo aparece en nómina como celador de pailas en la planta de generación de vapor, con un salario de $\$ 80.00$.

- (B) Sueldos zafra: la subcuenta aparece en los meses de enero a mayo, con nueve obreros de febrero a mayo y solo cinco en enero. La subcuenta se relaciona con la actividad de ferrocarriles. En la nómina no se hace distinción entre el corredor de locomotora de vía pública, vía interior o patio. En el caso de los fogoneros, solo se hace distinción entre el fogonero y el fogonero de patio. Aparecen además obreros con el trabajo de chuchero, actividad no descrita en la legislación, quienes recibían un salario pagado de $\$ 47.00$.

- (P) Rep. y limpieza de líneas: aparecen de cinco a siete trabajadores en los meses de enero y mayo, con excepción de marzo, en pleno periodo de zafra, mes en que se registran veinte trabajadores. Los obreros enumerados en esta columna son un primer capataz con un salario de $\$ 110.00$, un segundo capataz con un salario de $\$ 100.00$ y el resto de los trabajadores, todos peones, que ganaban $\$ 1.00$ diario. La legislación solo incluye un capataz con un salario de $\$ 51.00$ mensual, sin alusión a peones.

- Cuenta 63: relacionada con todo el proceso de fabricación, incluye las labores correspondientes a los incisos C) Salario de maquinaria, D) Departamento de Electricidad, F) Departamento de Fabricación, G) Piso de Azúcar y H) Sección de Laboratorio, de la legislación laboral.

- (A) Sueldos generales: relaciona los sueldos correspondientes al jefe de Fabricación y al Departamento de Laboratorio, con ocho trabajadores 
en los seis primeros meses del año. De abril a mayo pasa a ser la subcuenta (H) Laboratorio, que se corresponde dentro de la legislación con el propio inciso H) Sección de Laboratorio. Los cargos de jefe de Fabricación y de jefe químico no aparecen en la legislación ni en el inciso $\mathrm{F}$ ), tampoco en el $\mathrm{H}$ ), pero en la nómina aparecen registrados con un salario de $\$ 400.00$ y $\$ 187.00$, respectivamente. Se corresponden en todo el año con los nombres declarados por los Manuales azucareros, Julio C. González, superintendente y Crescencio Moreira, jefe químico, ambos de nacionalidad cubana. Aparece además en nómina un auxiliar segundo con un salario de $\$ 60.00$.

- (B) Tachos y EF. Evaporación: con el inicio de la preparación de la zafra, en enero solo aparecen seis obreros, pero a partir de febrero y hasta junio se evidencia un aumento a quince obreros. Las labores relacionadas en nóminas se encuentran dentro del inciso F) Departamento de Fabricación.

- (C) Planta generación de vapor: aparece solamente en los seis primeros meses del año, con ocho obreros, a diferencia de enero, que solo cuenta con cuatro, mes en que se inician los preparativos para la molienda. Las labores correspondientes aparecen dentro del inciso C) Salario de maquinaria.

- (D) $\mathbf{S}$ y J. (sueldos y jornales) molienda: refleja el salario de los obreros vinculados a la molienda, de ahí que inicie a mediados de enero y hasta mayo, con la colaboración de entre 48 y 50 trabajadores en ese periodo. Se corresponde con del departamento C) Salario de maquinaria, de la legislación laboral.

- (E) Cristalizadores y centrífugas: solo contiene obreros de enero a mayo, con cantidad entre 25 y 48 . Sus labores aparecen asociadas en el inciso F) Departamento de Fabricación.

- (F) Piso azúcar: se reconocen los obreros que en la legislación laboral coinciden con el inciso G) Piso de Azúcar. Los obreros reconocidos son entre 18 y 30 en el periodo que comprende de enero a marzo. En la nómina aparece además el oficio de peón de limpieza, con un salario de $\$ 43.00$ que no se reconoce dentro del inciso correspondiente a la legislación. 
- (G) Limpieza general: todos los trabajadores registrados en nómina son peones vinculados a la limpieza, como indica el nombre de la cuenta, con un salario de $\$ 30.00$ a $\$ 36.00$ cada uno, que dependería de las labores realizadas, pues todos tienen igual cantidad de días trabajados. A partir de mayo se transfiere a la cuenta $80(\mathrm{~K})$.

- (N) Sueldos y defecación: asociados al proceso de defecación, con una cantidad de obreros que oscila entre 24 y 31 ; solo se registran días trabajados de enero a marzo. Aparece en el inciso F) Departamento de Fabricación.

- (O) Planta eléctrica: solo aparece en el periodo de enero a mayo, coincidiendo con el tiempo de zafra. Se incrementa de un obrero en enero a tres en el periodo antes indicado. Se corresponde con el inciso D) Departamento de Electricidad, propio de la legislación. Tal como se expuso anteriormente, en 1940 el central Santa María S. A. no estaba electrificado, solo hacía uso de la electricidad para el alumbrado del Central y el impulso de pequeñas bombas, lo cual se corresponde con la cantidad de obreros que eran empleados para tales funciones.

- (U) Manipulación bagazo: los obreros fluctúan entre 9 y 11 en el periodo de enero a junio. No se identifica ningún inciso asociado directamente con las labores registradas en la nómina, las cuales son chofer de tractor, manipulación de bagazo y peones, trabajadores cuyos salarios registrados son de $\$ 75.00,67.00$ y 36.00 , respectivamente. Por el momento productivo en que se genera el bagazo, debería estar relacionado con el Departamento de Fabricación.

- Cuenta 64: relacionada con labores no especializadas de la producción de azúcar, razón por la que no aparece vinculada a ningún inciso de la legislación, pero para efectos contables, sus montos salariales deben ser considerados como gastos.

- (A) Sueldos casa vivienda: solo registra a un único trabajador en todo el año, en este caso, una mujer de origen español. Llama la atención que durante el periodo de zafra aparecen como trabajados todos los días sin descanso, con un salario mensual de $\$ 31.00$. 
- (G) Caminos, aceras y etc.: aparece en la segunda quincena de mayo. Al terminar la zafra, los obreros se reubicaban en las labores de reconstrucción de caminos y aceras.

- (L) Establos: durante todo el año aparecen registrados tres trabajadores, con excepción de mayo y junio, cuando se registra un trabajador más. La nómina muestra dos caballerizos con $\$ 44.00$ de salario cada uno, y dos auxiliares con $\$ 37.00$. La labor de los establos no se encuentra recogida en la legislación, pues esta se refiere a los obreros especializados en la industria azucarera. Los establos son parte de la hacienda del dueño, pero no vinculado obligatoriamente a la producción de azúcar. Como ha sido descrito ya, parte de las propiedades de Esteban Cacicedo estaban destinadas a la crianza de ganado, lo que justifica los obreros en estas labores.

- (M) Gastos no clasificados o cuadrilla batey: aparece indistintamente en el año. Se registran dos capataces con salarios entre $\$ 80.00$ y $\$ 90.00$, el resto eran peones con salario de $\$ 1.00$ a $\$ 1.10$ el jornal. En algunos meses aparece como cuenta 62(P) Jornales de limpieza y reparación.

- (N) Reparación cercas: el número de trabajadores que aparecen oscila entre 25 y 31 solo de febrero a abril. Hay un mayoral con un salario de $\$ 73.00$, un auxiliar con salario de $\$ 44.00$, un peón principal con salario $\$ 35.00$, y los restantes son todos peones con un salario de $\$ 1.00$ el jornal (ver cuenta 61A).

- Cuenta 65: descrita al inicio del epígrafe en tabla 5 y otros análisis declarados aquí.

- (A) Sueldos administración general: no aparecen marcados los días trabajados en el mes; se corresponde con los dueños del central. Su registro en nómina refiere algún tipo de trabajo administrativo por el cual se cobró un salario, lo que significaba no solo participar como dueño de las ganancias de la sociedad anónima.

- (B) Sueldo de administración y oficina: sí se marcan los días trabajados, al igual que los trabajadores vinculados a la producción de azúcar, que no registran domingos libres en el periodo de zafra. Nótese que después de los salarios de la administración general, el salario más 
alto es el del contador, lo que muestra la importancia de su labor en el registro y control de la información económica generada por el central.

- (C) Gastos legales: este abogado consultor no tiene marcado días de trabajo, lo cual infiere que se le pagaba un salario para responder en todo asunto legal que pudiera necesitarse en cualquier momento del año.

- (I) Médico, enfermero, etc.: el enfermero trabajaba todos los días del mes, que aparecen marcados en la nómina. En el caso del médico no se marcan los días de trabajo, lo que supone que solo se hizo uso de sus servicios cuando fuesen necesarios. De ahí que el salario del enfermero es superior al del médico.

- (N) Policías: los tres policías trabajaban todos los días en tiempo de zafra, incluidos los domingos libres. En el resto del tiempo, uno de ellos tenía libre los sábados, lo que garantizaba que el domingo hubiese agente policial para velar por el orden ante cualquier situación delictiva.

- (O) Inspección colonias: los inspectores tampoco tenían marcados los días que trabajaban. De acuerdo con la legislación de 1940, el único inspector que aparecía registrado lo hacía en el inciso A) Departamento de Campo, que bien podía relacionarse con estos inspectores de colonias.

- Cuenta 66 (B) estiba y peones: esta cuenta solo aparece en enero y julio, en los preparativos para el inicio de la zafra y al concluir esta. Todos eran peones, la mayoría iniciaron a mediados de enero, con un salario que oscilaba entre $\$ 30.00$ y $\$ 49.00$. Además de estar asociados a los días trabajados necesariamente, también lo estaban a la labor que desempeñaban, porque algunos que trabajaron trece días ganaron lo mismo que otro que trabajó solamente tres días.

- Cuenta 69: las subcuentas que aparecen en todo el periodo no guardan relación entre sí en cuanto a funciones; una se corresponde con el inciso A) Departamento de Campo, de la legislación laboral, y la otra con el inciso C) Salario de maquinaria.

- (E) Pesadores caña batey: solo aparecen tres obreros en los cuatro primeros meses del año. Corresponden al inciso A) Departamento de Campo, de la legislación laboral. Estos obreros trabajaron uno por turno.

- (F) Manipulación basculador: se extiende de enero a mayo, con aproximadamente veinte trabajadores en los meses de zafra. Estas 
labores se encuentran dentro del inciso C) Salario de maquinaria. Se hace diferencia en la nómina entre el capataz de basculador y el capataz auxiliar, el último con un salario de $\$ 53.00$ mensual.

- Cuenta 72: se relaciona con los salarios del taller de maquinaria en varios meses del año, así como con la labor de carpinteros y albañiles; estos últimos se corresponden con lo estipulado en la legislación en los incisos I) Sección de Carpintería y J) Sección de Albañilería, respectivamente.

- (O) Taller maquinaria: correspondiente a los salarios del taller de maquinaria, que aparece en enero y luego de junio a diciembre. En febrero y marzo se une a la cuenta 63 D) Sueldos de la molienda. A su vez, en abril y mayo pasa a la cuenta $80 \mathrm{~A}$ ) Sueldos.

- (P) Carpintería: durante todo el año trabajaron cinco carpinteros: dos carpinteros de primera, dos de segunda y un peón. Solo en enero se emplearon dos peones. Se corresponde con el inciso I) Sección de Carpintería. En el registro de nómina aparece el salario de los peones (\$38.00), actividad que no aparece registrada en la legislación. Pasado el periodo de zafra, los salarios descienden por mes de $\$ 77.00$ a $\$ 48.00$ para el jefe de carpinteros y los carpinteros de primera, de $\$ 67.00$ a $\$ 42.00$ para los de segunda y de $\$ 1.70$ aproximadamente a $\$ 1.25$ por jornal para los peones.

- (Q) Albañilería: se registran tres obreros en los meses que no son de zafra, duplicándose a seis obreros durante el tiempo de zafra. Se corresponde con el inciso J) Sección de Albañilería. Se reportan un único albañil y cinco peones; esta última labor no es considerada en la legislación y se registra con un salario pagado en nómina de $\$ 36.00$ pagado en el mes durante el periodo de zafra. Fuera de dicho periodo, el salario del albañil disminuye a $\$ 42.00$ el mes, y el de los peones a $\$ 1.10$ por día. En algunos meses la subcuenta $(\mathrm{Q})$ aparece con un mismo contenido en obreros y salarios, pero con el nombre de Gastos no clasificados.

- Cuenta 77 (A) Sueldos: se evidencian tres trabajadores en todo el año: un montero con un salario de $\$ 46.00$ y dos peones con un salario de $\$ 36.00$ cada uno. Esta labor no está vinculada directamente con el proceso productivo del azúcar, por eso no aparece registrada en la legislación laboral azucarera. 
- Cuenta 80: solo de abril a junio aparece esta cuenta, que absorbe el registro correspondiente a los sueldos y jornales de un número de cuentas antes mencionadas, las que posterior a junio retoman su número de cuenta. En la revisión de nómina se comprueba que son las mismas cuentas y subcuentas, puesto que los nombres de los obreros, su nacionalidad y sus puestos de trabajo son los mismos. En todos los casos el salario mensual tiende a disminuir aproximadamente en $\$ 20.00$. Esta situación también ocurre en 1941, pues, al parecer, no muy común el tratamiento, se realizó la comprobación de la nómina del siguiente año.

De febrero a mayo, la mayoría de los obreros tienen marcados todos en la nómina los días del mes como trabajados; solo hasta junio vuelven a aparecer los domingos sin marcar, como día de descanso. Esta situación generó que en el propio mes de junio algunos trabajadores comenzaran trabajar a partir de la segunda quincena, por ejemplo, en taller de maquinaria y carpintería; en otros departamentos se intercalan los obreros entre la primera y segunda quincena, por ejemplo, en las oficinas, los policías y caballerizos.

En la revisión de la nómina se detecta, además, una serie de acciones con carácter dudoso y que ponen en evidencia la no confiabilidad de la información recogida en este, tal como se expone en los siguientes ejemplos:

En enero se altera el número total de trabajadores, pues la cuenta 62(P) Jornales de peones aparece dos veces en diferentes lugares de la nómina, con los mismos cinco peones, contando como si fueran diez. En la primera ocasión se registraron por el trabajo correspondiente hasta el día diez del mes, y luego, en el segundo registro, por labores realizadas, del 15 al 30 del mes. También se deja un número en blanco sin datos de trabajador, pero que cuenta al final como un trabajador más.

En febrero, en la cuenta 64(N) se registran 47 trabajadores, 22 de ellos repetidos; primero se les marca una quincena y luego la segunda. Lo mismo ocurre en la cuenta 62(P) Reparación y limpieza de líneas, en la que cinco peones aparecen registrados dos veces. Tal como en enero, el número de 
obreros en la nómina se incrementa; situación similar ocurre en marzo en las mismas cuentas.

En julio, en la cuenta 64(L) Establos aparece un cuarto trabajador, pero en todo el periodo habían sido tres. Llama la atención que se enumera este cuarto trabajador como 59A, en tanto que el trabajador anterior tiene el número 59. Además, su registro está escrito con otro color de tinta; en su caso no aparecen marcados los días trabajados y en el total de días trabajados le reconocen 26 días, al igual que a los demás peones, aunque en la sección de horas solo le declaran las horas trabajadas en el mes y ninguna anterior, por lo que solo acumula la misma cantidad de horas, 26 días trabajados por ocho horas diarias igual a 208 horas totales en el mes.

La cantidad anual de trabajadores registrados en la nómina oscila entre 116 a 302; este último número se reporta en marzo durante el periodo más alto de trabajo en la zafra. Cuando se analiza la información presentada en los Anuarios azucareros de Cuba, aparece que, en 1940, el Central Santa María S. A. contó para la zafra con aproximadamente 2000 trabajadores. Esta alta diferencia entre la nómina y los Anuarios puede estar determinada, en gran medida, por la cantidad de obreros que intervenían en el corte, el alza y el tiro de la caña, que no eran registrados por el propio central, sino por los colonos, y que, además, en el caso de este central, como ya se ha expuesto, el 98 \% de la caña provenía de los colonos.

Aun así, la posibilidad de que otras personas trabajaran para el central sin ser reconocidos en nóminas era una realidad. Hasta nuestros días llegan los testimonios de personas que trabajaban para los ingenios o centrales y no aparecían registrados en ningún libro, ya fuese por la corta edad o por ser contratados por un tercero que pagaba el precio de su labor.

Otro análisis que permite realizar el libro de nóminas se relaciona con el monto total de los salarios devengados como diferencia entre el alcance y la cantidad que ya había sido anticipado a los trabajadores antes del cobro al mes correspondiente. En 1940, el 17 \% del salario total correspondió a anticipos, y el $83 \%$ al salario devengado. 
Parte de los salarios se anticipaba en productos que se vendían en la tienda del batey, lo cual constituía una vía de rápido retorno de los fondos invertidos por el propietario del central, donde el obrero, en muchos casos, no percibía la mayor parte de su salario en efectivo. A esto también se añadían los anticipos en caso de enfermedad, cuyos costos eran pagados por el propietario del central y se descontaban luego del salario final que el obrero devengaba.

En el libro de nómina, la columna de anticipo aparece solamente en enero con el nombre de efectivo a cuentas; tal diferenciación puede ser considerada como crédito otorgado en efectivo hasta la fecha de pago del salario. El anticipo representaba para los dueños mucho más que un mecanismo contable, una forma de ejercer autoridad.

Además de ser documentos primarios del registro de la información referida al pago de los salarios por departamentos y labores, las nóminas constituyen una valiosa fuente de información de la vida social y laboral de los pueblos donde existieron centrales azucareros, en lo referido a nombres y apellidos de familias, nacionalidad de los obreros, días de descanso, ubicación laboral por temporadas y otras.

\section{Conclusiones}

1. El tema salarial en la industria azucarera en Cuba tiene sus particularidades, asociadas al propio desarrollo del cultivo de este producto, a las tecnologías relacionadas con su fabricación, a la mano de obra empleada para las plantaciones y producción de azúcar, así como a las regulaciones laborales que estuvieron vigentes en cada periodo.

2. La puesta en vigor del Acuerdo n. $^{\circ} 50$ por la Comisión Nacional de Salarios Mínimos en 1940 vino a complementar lo establecido en el capítulo V del Reglamento de la Ley de Coordinación Azucarera. Esta medida pretendía las mejoras salariales de los trabajadores de la industria azucarera; en el caso del Central Santa María S. A., se evidencia que los salarios registrados en varias labores eran superiores a los salarios mínimos establecidos por la legislación. 
3. Desde los inicios de la partida doble como método de registro de la contabilidad, las prácticas contables son apreciadas en el libro de nómina de sueldos y jornales del Central Santa María S.A. en 1940, tales como punteo de operaciones, dobles rayas en los montos totales, signos de pesos al inicio de cada columna, dos lugares después de la coma al final de cada monto, legalización de libros de cuentas, cierre del total de cada folio y paso al siguiente, limpieza y claridad en la escritura, así como la paginación consecutiva de los folios.

4. En el libro de nóminas de sueldos y jornales del Central Santa María S. A. se reconoce una gran cantidad de cuentas y subcuentas empleadas para el registro de los gastos por concepto de salario por departamentos, las que varían de clasificación en momentos determinados del proceso productivo. Esta es una muestra de la carencia de sistemas contables estandarizados en esta época en el país.

\section{Bibliografía}

Anuario Azucarero de Cuba. (1937-1959). La Habana, Cuba: Cuba Económica y Financiera

Aguirre, S. (1964). Ponencia presentada en el intercambio de opiniones entre teóricos agrarios marxistas celebrado en julio-septiembre de 1960 en La Habana y Bucarest. En La cuestión agraria y el Movimiento de Liberación Nacional. Praga: Editorial Paz y Socialismo.

Barrero, N. y González, Y. (2012). Archivo Histórico del Patrimonio Azucarero, análisis histórico-contable, periodo 1937-1941. (Tesis de Licenciatura. Departamento de Contabilidad y Finanzas). Universidad Central "Marta Abreu" de Las Villas. Villa Clara, Cuba.

Cubamuseo. (2015). Las fichas azucareras cubanas. Recuperado de http://www. cubamuseo.com/Seccion/14-es

Fernández, C. (1947). Contabilidad de ingenios azucareros (tomo I). (1. ed.). La Habana, Cuba: EMECSA.

García, G. (1983). General de las cañas. Cuba: Editora Política.

González, M. (2012). Historia de Ifraín Alfonso. Fórum de Ciencia y Técnica, Central Ifraín Alfonso. Ranchuelo, Cuba. 
Moreno, M. (1978). El ingenio. La Habana, Cuba: Editorial de las Ciencias Sociales. Pacheco, M. (2008). La historia me absolverá: el triunfo de la justicia. En Librínsula. La Isla de los libros, 222. Recuperado de http://librinsula.bnjm.cu/secciones/222/nombrar/222_nombrar_4.html

Pacioli, L. (1494). De las cuentas y las escrituras. En Summa de Aritmetica, Geometria, Proportioni et Proportionalita (título noveno, tratado XI). Venecia: Paganino de Paganini.

Pérez, R. (1942). Legislación azucarera (tomo II). La Habana, Cuba: Editorial Selecta.

Portilla, J, (1987). Jesús Menéndez y su tiempo. La Habana, Cuba: Editorial de Ciencias Sociales.

Rebello, C. (1860). Estados relativos a la producción azucarera de la Isla de Cuba, formados competentemente y con autorización de la Intendencia de Ejército y Hacienda. La Habana, Cuba: Intendencia de Ejército y Hacienda.

Torres-Cueva, E. y Loyola, O. (2002). Historia de Cuba 1492-1898. Formación y liberación de la nación. La Habana, Cuba: Editorial Pueblo y Educación.

Zanetti, O. (2004). El colonato azucarero cubano en 1959. Revista Bimestre Cubana, $X C V(20), 1-48$.

Zanetti, O. (2009). Economía azucarera cubana. Estudios históricos. La Habana, Cuba: Editorial de Ciencias Sociales.

\section{Otra documentación consultada:}

Fuente: Archivo Histórico Provincial de Santa Clara

Fondo: Complejos Agroindustriales Azucareros

Mayor de Colonos

Nóminas del central Ifraín Alfonso 1940

Legislación Laboral 1941

Manuales de la Industria Azucarera Cubana 1937-1944 